\title{
Orientation behavior of predaceous ground beetle species in response to volatile emissions identified from yellow starthistle damaged by an invasive slug
}

\author{
Marina Oster $\cdot$ Lincoln Smith $\cdot$ John J. Beck • \\ Abigail Howard • Christopher B. Field
}

Received: 22 March 2014/ Accepted: 21 July 2014/Published online: 7 August 2014

(C) The Author(s) 2014. This article is published with open access at Springerlink.com

\begin{abstract}
We investigated indirect defense in the yellow starthistle (Centaurea solstitialis)-grey garden slug (Deroceras reticulatum)-ground beetle (Pterostichus melanarius and Scaphinotus interruptus) system. In this host plant/ herbivore/predator system, the ground beetles are the primary predator of $D$. reticulatum, the dominant herbivore of the highly invasive weed, $C$. solstitialis. The aim of our study was to examine the behavioral responses of two species of ground beetle to olfactory stimuli emitted from yellow starthistle damaged by $D$. reticulatum. The beetle $P$. melanarius showed a significant preference for the odor of damaged yellow starthistle relative to the odor of intact plants, while $S$. interruptus did not. Volatiles from $D$. reticulatum-damaged yellow starthistle were collected and identified as trans- $\beta$-farnesene, germacrene $\mathrm{D}$, bicyclogermacrene, and 1,5,9-trimethyl-1,5,9-cyclododecatriene. No quantitative relationship was observed between beetle plant choice or decision time and the level of herbivory. Similarly, there was no relationship between volatile compound relative abundance and level of herbivory, suggesting that our range of leaf damage produces either
\end{abstract}

Handling Editor: Jarmo Holopainen.

M. Oster $(\bowtie) \cdot$ A. Howard

Department of Biology, Stanford University, Stanford, CA 94305, USA

e-mail: mrus@stanford.edu

M. Oster · C. B. Field

Department of Global Ecology, Carnegie Institution for Science, Stanford, CA 94305, USA

L. Smith · J. J. Beck

Agricultural Research Service, United States Department of Agriculture, Albany, CA 94710, USA undetectable semiochemicals or no variation in volatile emission.

Keywords Volatile organic compound - Centaurea solstitialis - Indirect defense - Pterostichus melanarius . Scaphinotus interruptus $\cdot$ Deroceras reticulatum

\section{Introduction}

Nearly, all biogenic volatile organic compounds (VOCs) serve multiple ecological functions (Sharkey et al. 2001; Dudareva et al. 2006), such as in plant communication, and interest in their plant signaling role has recently increased (Tholl et al. 2006; Yuan et al. 2009). On a tri-trophic level, leaf consumption by herbivores may induce emission or up-regulation of plant volatiles, serving as a signal to natural predators and parasitoids that a plant is under attack. By attracting the natural predators and parasitoids of the plant herbivore, VOCs serve as an indirect inducible plant defense and offer competitive advantage (Turlings et al. 1990; Dicke et al. 1990; Vet and Dicke 1992; Heil 2004).

Tritrophic plant-herbivore-carnivore systems occur widely throughout nature (Price et al. 1980). Yellow starthistle (YST), Centaurea solstitialis L. (Asteraceae), is a winter annual native to the Mediterranean region that established in North America around the 1850s (Wilson et al. 2003; DiTomaso et al. 2006). It is a highly competitive and invasive weed with a strong potential for displacing native species and reducing biodiversity. YST emits a suite of volatile compounds (Buttery et al. 1986; Binder et al. 1990), including those implicated in indirect defense in other systems (Arimura et al. 2004; Beck et al. 2008), a mechanism which may be especially beneficial 
Fig. 1 The tritrophic system. a Centaurea solstitialis, b Deroceras reticulatum, c Pterostichus melanarius, d Scaphinotus interruptus. Photographs by R. Hernandez and M. Oster
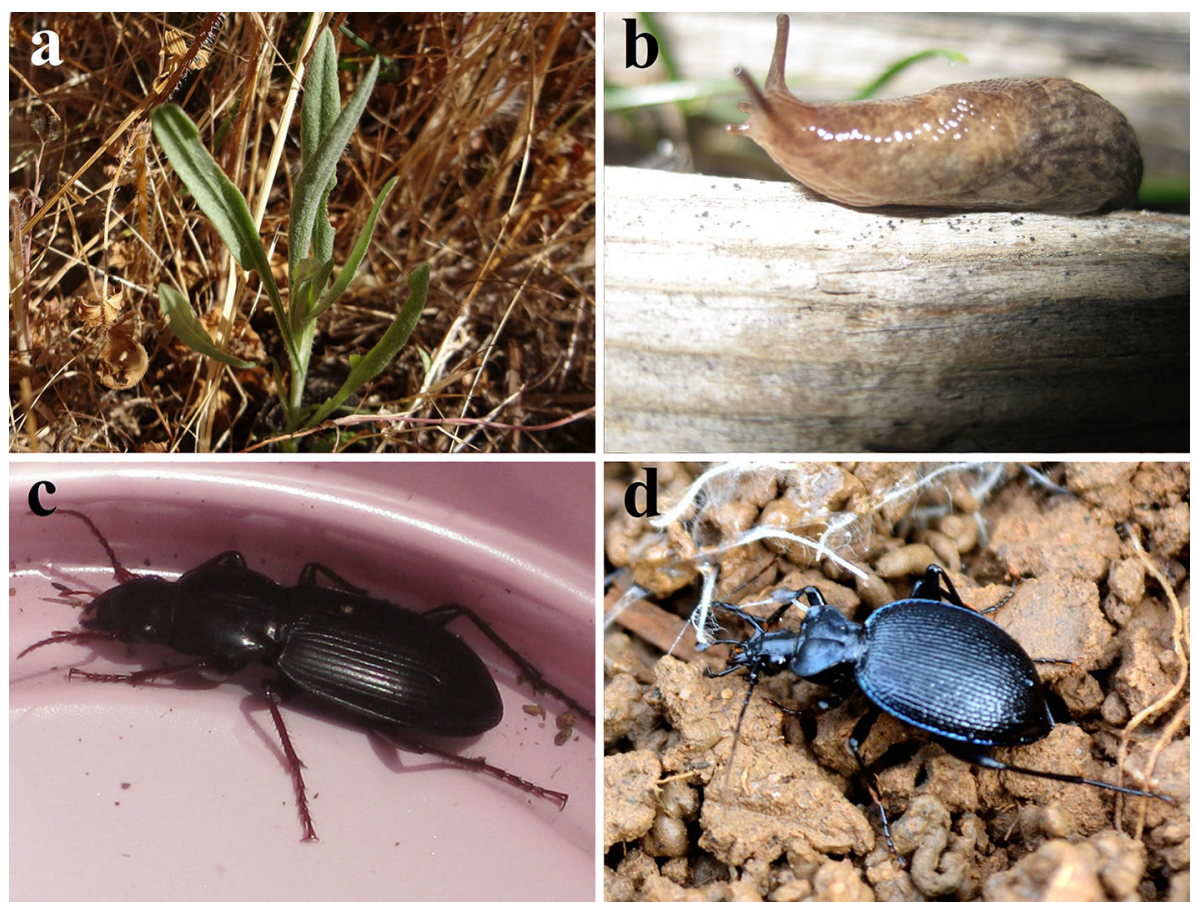

during the early growth stages of YST when physical defense is low. Its herbivore, Deroceras reticulatum (Müller) (Limacidae), or the grey garden slug, is indigenous to the Western Palaearctic region (South 1992) and has been accidentally introduced from Europe into most parts of the world (Getz 1959; Quick 1960). This species preferentially feeds on young leaves and seedlings (Hanley et al. 1995) and is implicated as a major herbivore of YST, consuming the weed in its early growth stages with high rates of sublethal damage or complete consumption (Woods et al. 2000; Oster et al. unpublished data). The third trophic level examined in this system is occupied by the ground beetles Pterostichus melanarius (Illiger) and Scaphinotus interruptus (Menetries) (Coleoptera: Carabidae)—dominant natural enemies and predators of the grey garden slug in the field (Ingram 1946; Cornic 1973; Oberholzer and Frank 2003; Tulli et al. 2009). Both species are nocturnal and take cover during the day (Kavanaugh 1992). P. melanarius was accidentally introduced from Europe and now maintains a Holarctic range and broad distribution (Lindroth 1961; Spence and Spence 1988). In contrast, S. interruptus is a beetle native to North America, occurring almost exclusively west of the Rocky Mountains (Weber and Kavanaugh 1992). In addition to slugs, it has been documented to feed on snails (Thiele 1977; Ingram 1946), but relatively little else is known about its biology.

To our knowledge, damaged YST has not been studied in the context of indirect defense, and correspondingly, no olfactometer work has been done with $S$. interruptus. The robustness of $D$. reticulatum as a natural enemy of $C$. solstitialis may depend on the sensitivity of slug detection by the above carabid species via indirect signaling. The aims of our study were to examine the behavioral responses of two species of ground beetle, P. melanarius and $S$. interruptus, to olfactory stimuli emitted from YST herbivorized by $D$. reticulatum (Fig. 1), and to identify the herbivore-induced volatiles.

\section{Materials and methods}

Tritrophic system

We collected adult beetles ( $P$. melanarius and $S$. interruptus), slugs (D. reticulatum), and YST (C. solstitialis) seeds in June 2012 from Stanford University's Jasper Ridge Biological Preserve located in San Mateo County, CA. The laboratory housed both species of ground beetles obtained from pitfall traps individually in $20 \times 15 \times 5 \mathrm{~cm}$ rectangular plastic containers with snap-on lids and 20 needle perforations to provide ventilation. Controlled temperature chambers kept the beetles at $17^{\circ} \mathrm{C}, 12: 12 \mathrm{~h}$ L:D photoperiod. The photoperiod was reversed, with the scotophase starting at 6:00 am, so that experiments with the nocturnal animals could be conducted in the dark during the daytime. Beetles received $10 \mathrm{mg}$ of fresh slug once 10 days before each trial so that each beetle experienced the same number of starvation days before olfactometer testing. The total number of replicates performed for each beetle was 33 for $S$. interruptus and 73 for $P$. melanarius. 
The same conditions applied to slugs obtained from underneath old boards with the addition of a sealed plastic bag surrounding the container to maintain moisture. Slugs fed for $24 \mathrm{~h}$ on cut YST leaves once every 2 weeks. Feeding was suspended 14 days prior to a slug's placement on a YST plant for herbivory. YST plants were grown from seed collected at Jasper Ridge in a greenhouse and watered every 2 days. The study used three-week-old plants, $17-20 \mathrm{~cm}$ in height. Undamaged plants had no contact with slugs.

\section{Experiment 1: olfactometry}

Two slugs were placed on each plant and enclosed by a mesh covering for $24 \mathrm{~h}$ to produce damaged plants and then removed immediately prior to olfactometer use. The leaf amount eaten ranged from 26 to $299 \mathrm{~mm}^{2}$, representing approximately $2-25 \%$ of the total area of each damaged leaf. The olfactometer experiment used a total of 7 damaged and 7 undamaged plants. Approximately 17 beetles were tested per day. Only one pair of damaged and undamaged plants was utilized each day so beetles could be tested with the same plant on a given day. Each plant pair was tested together, without being switched around. The Y-tube olfactometer testing beetle response was designed as follows: One whole damaged and one whole undamaged YST plant were each placed in a sealed one-gallon glass jar in a lit room for at least $4 \mathrm{~h}$ before a trial at $20^{\circ} \mathrm{C}$. The lid of each jar with YST contained two tubing outlets for in/out airflow. Medical grade air was released at a flow rate of $250 \mathrm{ml} / \mathrm{min}$ and split to each plant jar. Lastly, each arm of the glass Y-tube connected to one of the two jars through tubing and a glass bulb that fit into each arm. Given the nocturnal activity of both the carabids and gastropod, a $120 \mathrm{~V}$ R30 red incandescent bulb hung above the center of the Y-tube. The experiment took place in a windowless laboratory room while the lamp allowed for observation of activity in conditions perceived by the beetle as dark (Fig. 2a). Two Y-tubes were alternated between runs and washed with ethanol, dried, and cooled to room temperature. Reversing the position of the arms accounted for arm bias while alternating Teflon ${ }^{\circledR}$ tubes connected to each jar ensured that there was no difference in beetle response between one air type going through Arm 1 or Arm 2 (i.e., air from damaged plant flowing through Arm 1 had the same beetle response as when flowing through Arm 2). Recording of beetle behavior occurred every $30 \mathrm{~s}$. The beetle was given a maximum of 15 min to make a decision. A choice was recorded when the beetle reached the end of an arm (where the arm joined the glass bulb) and remained there for at least $30 \mathrm{~s}$. If no decision was made within $15 \mathrm{~min}$, it was deemed no choice.

Experiment 2: volatile collection after herbivory

The in situ volatile collection experiments were performed as similarly described (Beck et al. 2008) and occurred during morning hours with lighting present in the same laboratory conditions as Experiment 1 at $20{ }^{\circ} \mathrm{C}$. Prior to volatile collection, slugs were placed on the leaves of an intact plant enclosed inside a 2,000-ml glass beaker covered by mesh for $3.5 \mathrm{~h}$, producing 9 damaged plants for volatile collection ( 2 additional damaged plants were utilized for further compound verification via a second column). Leaf amounts eaten per plant ranged from 40 to $410 \mathrm{~mm}^{2}$. Control experiments were performed to determine the background volatile profiles of the slug trail $(n=5)$, plants with undamaged leaves $(n=7)$, and empty bags $(n=5)$ using the same collection protocol as the slug-damaged plants.

A $10.2 \times 25.4 \mathrm{~cm}$ customized Teflon ${ }^{\circledR}$ bag (Welch Fluorocarbon, Dover, New Hampshire) (Beck et al. 2008) was utilized for solid phase micro-extraction fiber (SPME) insertion. A SPME (Supelco, Bellefonte, PA; $100 \mu \mathrm{m}$, polydimethylsiloxane fiber) needle was inserted through the port septum and allowed to adsorb volatiles for an exposure period of $2 \mathrm{~h}$ (Fig. 2b). A laboratory stand $(30.5 \mathrm{~cm})$ with two horizontal rods was positioned next to each plant. The plastic connection of the top outlet port was held up via a twist tie to the lower rod. The Teflon ${ }^{\circledR}$ bag was secured over the plant by folding the base of the bag over a rectangular piece of Teflon ${ }^{\circledR}(6.35 \times 1.59 \times 0.16 \mathrm{~cm})$ on each side of the stem and secured with a large binder clip.

Collected volatiles were directly injected and thermally desorbed on either a J \& W Scientific (Folsom, CA) DBWax column $(60 \mathrm{~m} \times 0.32 \mathrm{~mm}$ i.d. $\times 0.25 \mu \mathrm{m})$ installed on a HP-6890 N gas chromatograph (GC) coupled to HP5975B mass selective detector (MSD) (MS; Palo Alto, CA) or a J \& W Scientific DB-1 column $(60 \mathrm{~m} \times 0.32 \mathrm{~mm}$ i.d. $\times 0.25 \mu \mathrm{m}$ ) installed on a HP-6890 GC coupled to HP-5973 MSD. Desorbed volatiles were analyzed using methods previously published (Beck et al. 2008). NIST, Wiley, and internally generated databases were used for fragmentation pattern identification. The retention indices (RIs) were calculated using a homologous series of $n$-alkanes on DBWax and DB-1 columns. Volatile identifications were verified by comparison to authentic sample retention times and fragmentation patterns. Chemical standards were obtained as follows: trans- $\beta$-farnesene (Bedoukian); germacrene D (isolated by previous ARS researchers); 1,5,9trimethyl-1,5,9-cyclododecatriene (Sigma-Aldrich). Bi- 

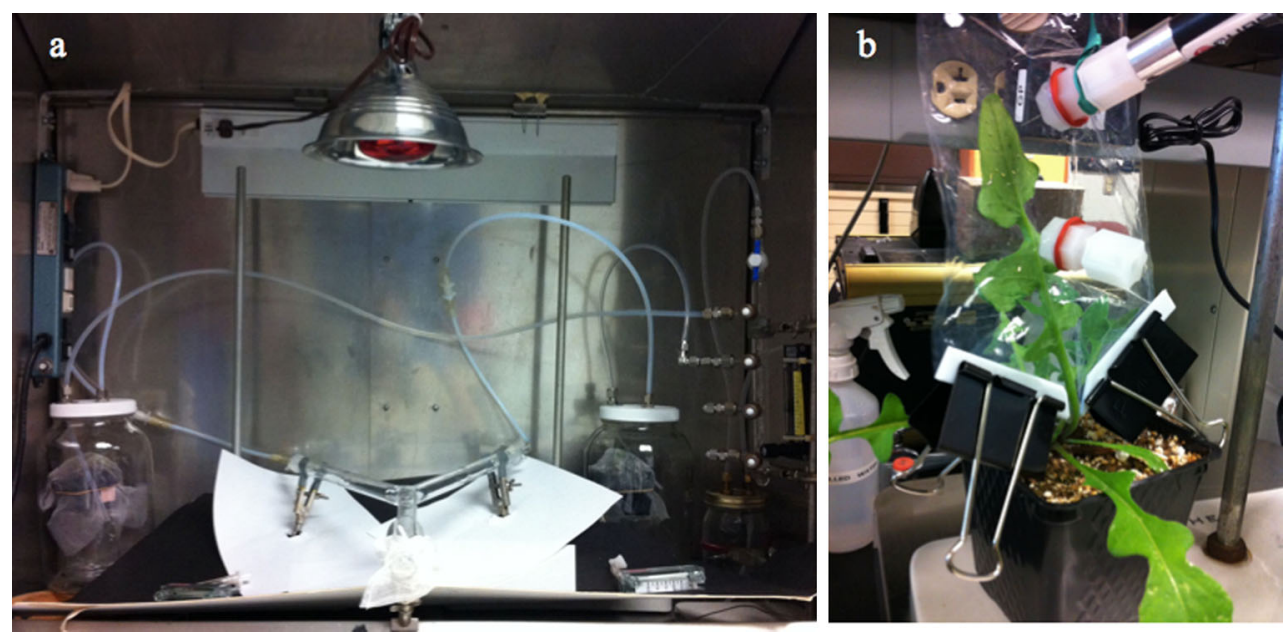

Fig. 2 a Y-tube olfactometer setup for behavioral assay, b volatile collection of $C$. solstitialis using a Teflon ${ }^{\circledR}$ bag and SPME. Photographs by M. Oster

cyclogermacrene was identified based on fragmentation pattern and retention indices on two columns.

Data analysis

\section{Experiment 1}

We performed the Pearson's chi-square test by predator species to determine significance in preference for damaged versus undamaged YST, analyzing the proportion of trials in which the insect chose odor A or odor B. Our null hypothesis stated that predators had equal preference for the two odor sources. Trials in which no choice was made were not utilized in the statistical analysis. The chi-square goodness-of-fit test was used to determine whether the response of $P$. melanarius differed from that of $S$. interruptus. Logistic regression ( $\mathrm{R}$ version 2.13.0) was performed to determine correlation between the proportion of damaged choices (beetle choice of damaged rather than undamaged YST) and the amount of leaf area eaten. A linear regression (log-transformed) tested whether the decision time for each beetle was affected by the amount of leaf area eaten. We used Kendall's tau coefficient twotailed test to assess presence of a trend. An ANOVA tested for interaction between pairs of the following variables: species, choice, and amount eaten.

\section{Experiment 2}

Data from GC-MS analyses were transferred to Microsoft Excel for comparison of retention times and compound identification for same-column analysis. Calculated retention indices were used to assist in compound identification: Samples were run on the DB-Wax column, while the DB-1

\section{Behavioral Response of Beetle Species}
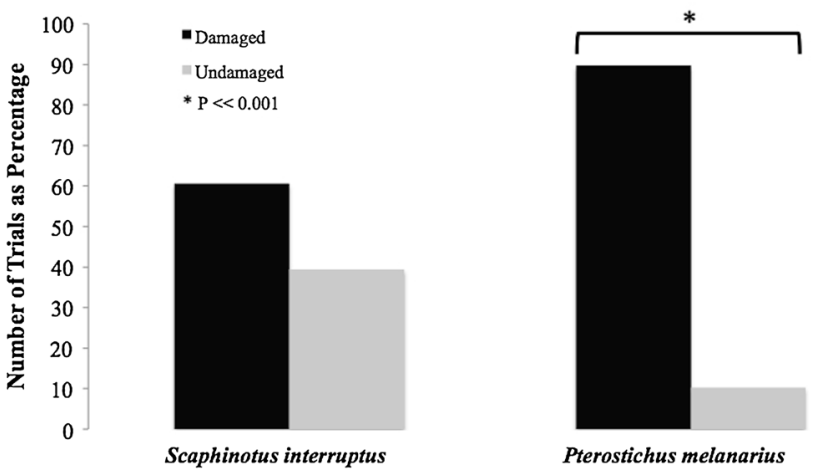

Fig. 3 Behavioral response of two beetle species in a Y-tube olfactometer. 'Damaged' signifies a beetle choosing the Y-tube arm attached to the damaged plant. 'Undamaged' signifies a beetle choosing the Y-tube arm attached to the undamaged plant. A choice was recorded when the beetle reached the end of an arm (where the arm joined the glass bulb) and remained there for at least $30 \mathrm{~s}$ within a 15 min trial

column was used for peak resolution and compound confirmation. We used Kendall's tau for testing association between volatile compound emission for each compound or for the sum of compounds and amount eaten.

\section{Results}

\section{Experiment 1}

P. melanarius showed a significant preference $(89.7 \%)$ for the odor of damaged versus undamaged YST in the Y-tube olfactometer $\left(\chi^{2}=42.88, P \ll 0.001,73\right.$ trials: 61 for damaged, 7 for the undamaged plant, Fig. 3). S. interruptus did not 


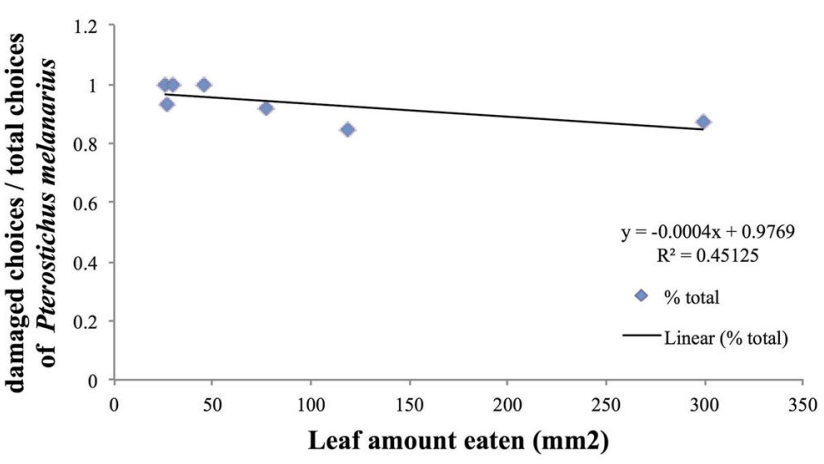

Fig. 4 The fraction of damaged YST choices as percentage made by each beetle species in response to the level of herbivory by $D$. reticulatum ( $P$. melanarius $P=0.31 ; S$. interruptus $P=0.097$ ).

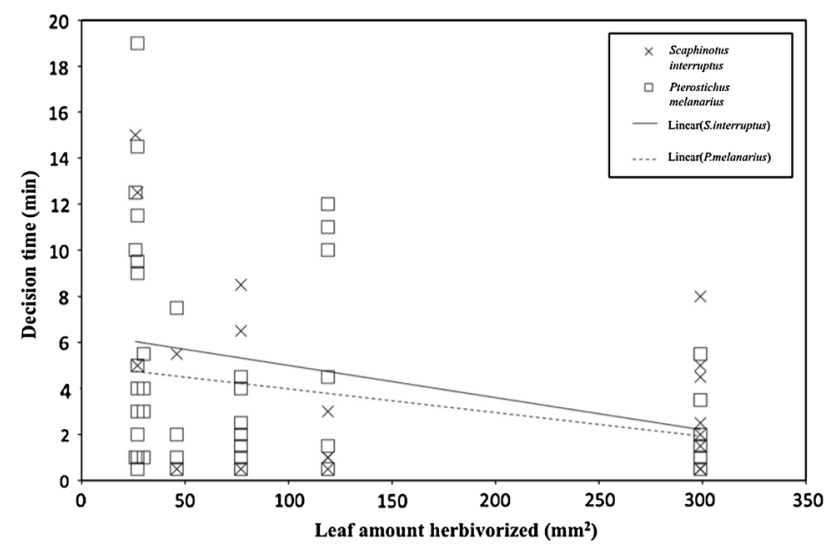

Fig. 5 Relationship between beetle response time and level of herbivory by $D$. reticulatum ( $P>0.05$ for both beetle species). Decision time is the interval beginning when a beetle was placed at the entrance of the Y-tube and ending when the beetle made a choice for damaged YST

show a significant preference for damaged YST (60.6\%; $\chi^{2}=1.48, P=0.22,33$ trials: 20 for damaged, 13 for undamaged). A goodness-of-fit test $\left(\chi^{2}=11.49, P \ll 0.001\right)$ confirmed that the species behaved differently. There was no significant difference between the two arms of the Y-tube with regard to $P$. melanarius $\left(\chi^{2}=2.36, P=0.12\right)$ and $S$. interruptus $\left(\chi^{2}=.004, P=0.95\right)$ choice. Air from the damaged plant attached to Arm 1 elicited the same beetle response as when the attachment was switched to Arm 2.

We also analyzed the behavioral responses of both carabids to levels of YST herbivory. The proportion of damaged YST choices over the total number of trials was plotted against the leaf area eaten (Fig. 4), revealing no relationship for either $P$. melanarius $(P=0.31)$ or $S$. interruptus $(P=0.097)$. Logistic regression also showed no correlation between probability of a damaged choice by $P$. melanarius and the level of herbivory $(P=0.38)$, but a positive relationship for $S$. interruptus $(P=0.032)$. However, when the trials for one plant with the highest level of herbivory were excluded, neither correlation

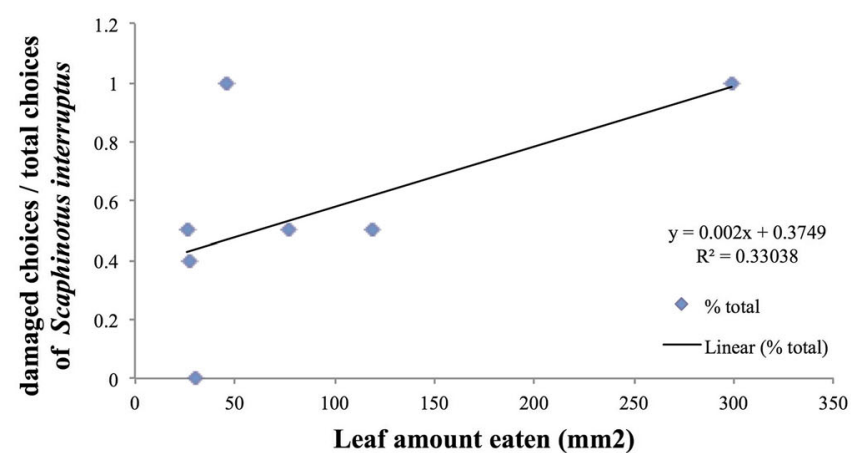

Fraction is defined as the ratio of trials in which a beetle species chose a damaged plant to the total number of trials in which the beetle made a decision

was significant $(P$. melanarius, $P=0.25, S$. interruptus, $P=0.70)$. There was no correlation for either species between decision time and the level of herbivory, based on linear regression $(P>0.05$ for both, Fig. 5) and Kendall's tau coefficient two-tailed test $(P>0.05)$. Decision time was also shown to not be affected by the individual plant used $(P=0.067,0.083)$ and time since plant damage $(P=0.81$, $0.56)$ for $P$. melanarius and $S$. interruptus, respectively. The majority of decisions occurred within $5 \mathrm{~min}$, although the longest beetle decision times were observed for plants with the least herbivory. An ANOVA confirmed the absence of interaction effects $(P>0.05$ for all variables).

Experiment 2

No VOCs from slug trail, plants with undamaged leaves, or empty bags were detected. Compounds unique to $D$. reticulatum-damaged YST confirmed by authentic standard and identified by comparison to the library or similar column were trans- $\beta$-farnesene, germacrene $\mathrm{D}$, bicyclogermacrene, and 1,5,9-trimethyl-1,5,9-cyclododecatriene (Fig. 6). Compounds and their average relative abundances are listed in Table 1. There was no statistically significant relationship between amount eaten and volatile relative abundance for each compound or for all four compounds taken as a single signal.

\section{Discussion}

Volatiles and beetle choice

No volatiles were detected from the undamaged YST plants in our study. This lack of volatile emissions from undamaged, intact YST has been noted in other reports (Beck et al. 2008). It is possible that the difference in plant age (and thus size) between studies plays a role: Our study utilized 3-week-old plants, while the other study collected 

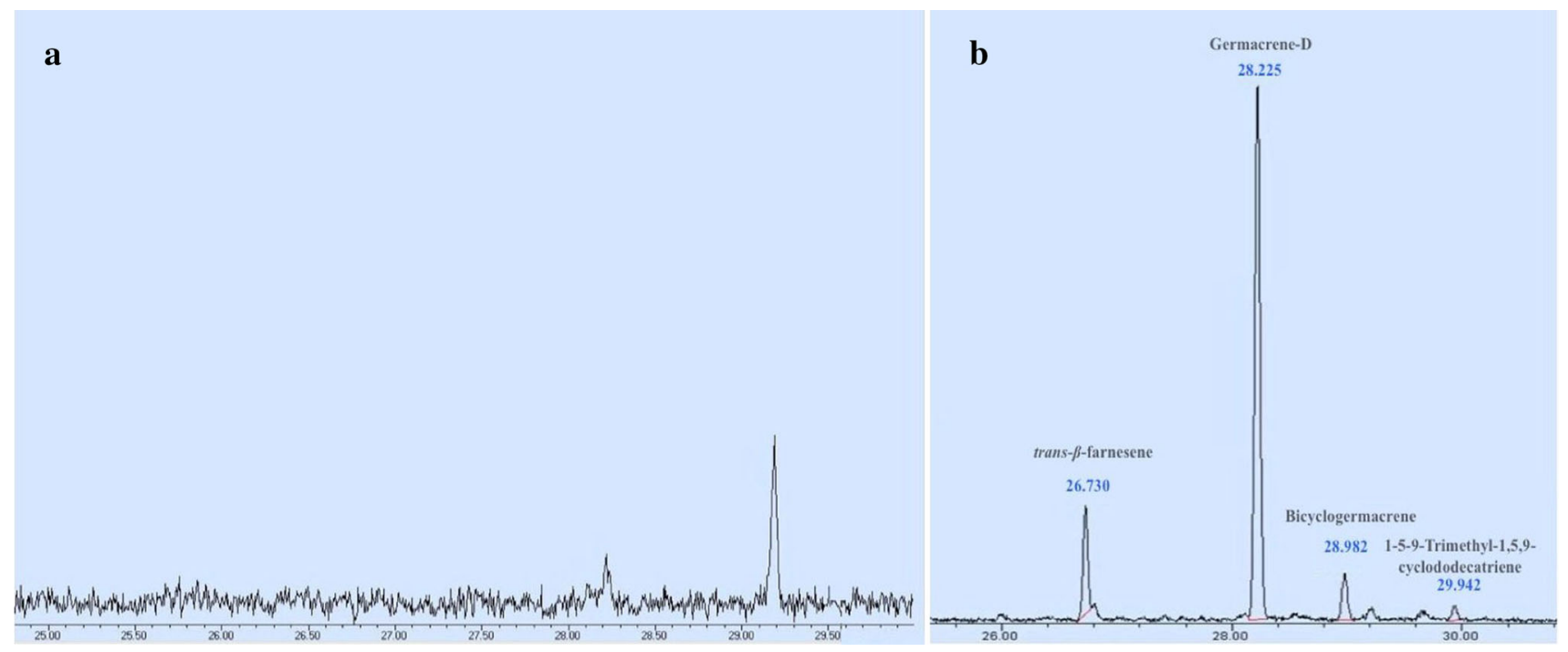

Fig. 6 Volatile compound chromatograms for a intact, undamaged YST pre-herbivory (visible peak is GC-MS contaminant), b damaged YST post-herbivory

Table 1 Identified YST volatiles

\begin{tabular}{|c|c|c|c|c|c|}
\hline RI & $\begin{array}{l}\text { Compounds } \\
\text { pre-herbivory }\end{array}$ & $\begin{array}{l}\text { Compounds } \\
\text { post-herbivory }\end{array}$ & Fragment pattern & $\begin{array}{l}\text { Relative } \\
\text { abundance }\end{array}$ & SEM \\
\hline 1662 & nd & trans- $\beta$-farnesene & 69(100), 41(80), 93(55), 67(25), 79(20) & 365,694 & 82,357 \\
\hline 1707 & nd & germacrene D & 161(100), 105(55), 91(50), 41(40), 81(37) & $1,031,914$ & 295,268 \\
\hline 1732 & nd & bicyclogermacrene & 121(100), 93(90), 41(55), 92(50), 107(47) & 206,393 & 46,305 \\
\hline 1801 & nd & 1,5,9-trimethyl-1,5,9-cyclododecatriene & $68(100), 67(40), 93(37), 107(30), 189(27)$ & 446,136 & 113,383 \\
\hline
\end{tabular}

$\mathrm{RI}=$ calculated retention indices relative to $n$-alkanes on a DB-wax column; nd = not detected; compounds pre-herbivory $=$ undamaged YST $(n=7)$; compounds post-herbivory $=$ slug-damaged YST $(n=9)$; fragment pattern $=$ five largest fragments $(\mathrm{m} / \mathrm{z})$ with relative percentages to that of the base peak (100) shown in parentheses; relative abundance = average per compound; SEM = standard error mean of each compound post-herbivory

volatiles from plants at 3-5 months of age. In our olfactometry assays, $P$. melanarius showed a significant preference for the odor of slug-damaged YST, while $S$. interruptus did not. Volatile analysis of the odor attracting $P$. melanarius showed to be comprised of four identified sesquiterpene compounds, three of which prominently figure in semiochemical activity (Gibson and Pickett 1983; Kielty et al. 1996; Weissbecker et al. 2000). Since isolated volatiles were not individually tested for beetle response, $P$. melanarius may be attracted to one or a combination of the identified volatiles. Germacrene D consistently had the largest relative abundance when compared to the other detected volatiles: 1,5,9-trimethyl-1,5,9-cyclododecatriene at approximately $45 \%$, trans- $\beta$-farnesene at $35 \%$, and finally bicyclogermacrene at $20 \%$. Germacrene D was also the most abundant compound in the case of mechanical YST damage (Beck et al. 2008). In other studies, the compounds germacrene $\mathrm{D}$, trans- $\beta$-farnesene, and bicyclogermacrene were part of the volatile blend attractive to the predaceous stinkbug when emitted by beetle-damaged potato plants (Weissbecker et al. 2000), suggesting indirect defense activity. The compound trans- $\beta$-farnesene is the main constituent of the aphid alarm pheromone and has been shown to attract $P$. melanarius to its aphid prey (Kielty et al. 1996). Further studies have shown it to be emitted by plants as an allomone to repel aphids themselves (Gibson and Pickett 1983). The compound 1,5,9trimethyl-1,5,9-cyclododecatriene has a high retention index (1801), which suggests a low volatility/vapor pressure. This reduces the likelihood of long-range travel in sufficient concentrations and thus requires that the beetle be in close proximity for detection. In addition, Beck et al. (2008) did not detect or report an unknown near this retention time with the described fragment pattern for mechanically damaged YST. The compound 1,5,9-trimethyl-1,5,9-cyclododecatriene may be a newly identified semiochemical which, to our knowledge, has not been previously detected in plant volatile emission and thus 
warrants further investigation. However, the response of $P$. melanarius to the compounds should be tested both as a blend and individually to conclusively identify semiochemical behavior in this system.

Our results show that unlike $S$. interruptus, $P$. melanarius responded to volatile stimuli from slug-damaged YST. $P$. melanarius, D. reticulatum, and C. solstitialis originated from Europe (Getz 1959; Quick 1960; Lindroth 1961; Spence and Spence 1988; Wilson et al. 2003), whereas $S$. interruptus is native to North America (Ingram 1946; Weber and Kavanaugh 1992). Thus, all three players in this tritrophic system (plant-herbivore-predator) have been introduced from overseas where they may have had time to coevolve an indirect defense mechanism. This may provide a mechanistic explanation for the often absent natural enemy pressure on introduced plants (Maron and Vila 2001; Agrawal and Kotanen 2003). For example, other studies have found that introduced plants experience a shift in natural enemies from specialist to generalist (Müller-Schärer et al. 2004), which may cause a lack of response from native herbivores or predators to novel volatile blends emitted from the introduced plant species (Wheeler and Schaffner, 2013).

Both carabid species are predators that consume slugs (Ingram 1946; Thiele 1977; Symondson et al. 1996). D. reticulatum has exhibited predator avoidance behavior toward $P$. melanarius, suggesting that $P$. melanarius may be an effective predator of $D$. reticulatum (Armsworth et al. 2005). S. interruptus appears to be physically adapted to prey on other food items such as snails (Ingram 1946, Thiele 1977), and slugs may be a novel prey item for this species. Compared to P. melanarius, S. interruptus has a larger body size, a thicker carapace, larger mandibles (Krumbiegel 1960), and spoon-shaped palpi (Thiele 1977), giving it the ability to break through snail shells (Ingram 1946; Thiele 1977). In contrast, P. melanarius, which eats slugs and aphids (Symondson et al. 1996), has a stout body with shorter appendages (Lindroth 1961). Visual cues apparently do not influence prey detection for these beetles. Both carabid species are nocturnal and do not demonstrate orientation toward prey when it is presented solely visually (Wheater 1989). D. reticulatum leaves trails of mucus that can be followed by conspecifics for up to $6 \mathrm{~h}$ after being produced (Cook 1979; Wareing 1986). However, we observed that both species of beetles did not appear to respond to presence of the slug trail mucus. Additionally, $P$. melanarius has not shown a preference for or attraction to slug mucus when presented on a plate at the outlet of a container in which the beetle was housed (Wheater 1989).

Trends in leaf amount eaten

After excluding trials for one plant with an extremely high level of herbivory $\left(299 \mathrm{~mm}^{2}\right)$, we detected no relationship for either species between the fraction of damaged choices made and the level of herbivory. Thus, this extreme point carries much influence, and more data would be necessary to confirm this relationship. Previous work performed on YST by others demonstrated that when varying degrees of mechanical damage were applied, an increase in the amount of damage to YST did not result in a significant increase in volatiles (Smith and Beck 2013). We observed no linear relationship between the amount of time beetles took to decide and the amount of leaf area damaged by $D$. reticulatum, which suggests that once YST has been damaged, the degree of herbivory does not play a significant role, possibly because there is not a significant difference in VOC concentrations. Furthermore, Experiment 2 showed that volatile levels did not correlate with the $\mathrm{mm}^{2}$ eaten by the slug.

It seems unlikely that the concentration in emissions was affected by the total plant size or by the amount of total plant area that remains after damage because both possibilities were controlled for: damaged and undamaged plants were the same age ( 3 weeks) and approximately the same size, in addition to there being no evidence of a plant-wide response or of individual plant effects (Smith and Beck 2013; Oster et al. unpublished data). Furthermore, the damaged leaves themselves were chosen to be very close in size (average surface area of $11.25 \mathrm{~cm}^{2}$ ), while damage only represented $2-25 \%$ of a single leaf. Finally, our result shows that beetle decision time was unaffected by time since plant damage is further supported by an experiment with mechanically damaged YST, where an immediate increase in volatiles after leaf puncture remained at consistently high levels over $48 \mathrm{~h}$ (Smith and Beck, unpublished data).

Both $D$. reticulatum and $P$. melanarius may serve as natural enemies to help control important pests: the slug as a control for YST within our system, and P. melanarius as a control for the slug, a common pest for other plant species. Thus, it may be important to assess future climate change effects on YST volatile emissions (McFrederick et al. 2009) and to monitor D. reticulatum and P. melanarius populations in order to better predict the future success of this invasive weed. Our study demonstrates the role of plant volatiles in recruiting a predator to its prey and has laid the groundwork for future $P$. melanarius and $S$. interruptus olfactometer studies.

Acknowledgments We would like to express gratitude to Nona Chiariello of Jasper Ridge Biological Preserve at Stanford University and Todd Tobeck of the Carnegie Institution for Science for providing field advice, to Robert Furrow for statistical expertise, and to Kara Yeung for aid in presentation and design. We also thank Wai Gee of the USDA Agricultural Research Service for providing technical knowledge. This Jasper Ridge Global Change experiment was supported by the National Science Foundation (Grant 091817), the Carnegie Institution for Science, and Stanford University. 
Open Access This article is distributed under the terms of the Creative Commons Attribution License which permits any use, distribution, and reproduction in any medium, provided the original author(s) and the source are credited.

\section{References}

Agrawal AA, Kotanen PM (2003) Herbivores and the success of exotic plants: a phylogenetically controlled experiment. Ecol Lett 6:1-4

Arimura G, Huber D, Bohlmann J (2004) Forest tent caterpillars (Malacosomadisstria) induce local and systemic diurnal emissions of terpenoid volatiles in hybrid poplar (Populustrichocarpa $\times$ deltoides $)$ cDNA cloning, functional characterization, and patterns of gene expression of (-)-germacrene D synthase, PtdTPS1. Plant J 37:603-616

Armsworth CG, Bohan DA, Powers SJ et al (2005) Behavioural responses by slugs to chemicals from a generalist predator. Anim Behav 69:805-811

Beck JJ, Smith L, Merrill GB (2008) In situ volatile collection, analysis, and comparison of three Centaurea species and their relationship to biocontrol with herbivorous insects. J Agric Food Chem 56:2759-2764

Binder RG, Turner CE, Flath RA (1990) Comparison of yellow starthistle volatiles from different plant parts. J Agric Food Chem 38:764-767

Buttery RG, Maddox DM, Light DM et al (1986) Volatile components of yellow starthistle. J Agric Food Chem 34:786-788

Cook A (1979) Homing by the slug Limaxpseudoflavus. Anim Behav $27: 545-552$

Cornic JF (1973) Etude du régime alimentaire de trois espéces de carabiques et de ses variations en verger de pommiers. Ann Soc Ent Fr 9:69-87

Dicke M, Abelis MW, Takabayashi J et al (1990) Plant strategies of manipulating predator-prey interactions through allelochemicals: prospects for application in pest control. J Chem Ecol 16:3091-3117

DiTomaso J, Kyser GB, Pitcairn MJ (2006) Yellow Starthistle Management Guide. Cal-IPC Publication 2006-03. California Invasive Plant Council, Berkeley, California. http://www.cal-ipc. org/ip/management/yst.php. Accessed 26 November 2011

Dudareva N, Negre F, Nagegowda DA et al (2006) Plant volatiles: recent advances and future perspectives. Crit Rev Plant Sci $25: 417-440$

Getz LL (1959) Notes on the ecology of slugs: Arion circumscriptus, Deroceras reticulatum, and D. laeve. Am Midl Nat 61:485-498

Gibson RW, Pickett JA (1983) Wild potato repels aphids by release of aphid alarm pheromone. Nature 302:608-609

Hanley ME, Fenner M, Edwards PJ (1995) The effect of seedling age on the likelihood of herbivory by the slug Deroceras reticulatum. Funct Ecol 9:754-759

Heil M (2004) Direct defense or ecological costs: responses of herbivorous beetles to volatiles released by wild Lima bean (Phaseoluslunatus). J Chem Ecol 30:1289-1295

Ingram WM (1946) Mollusk food of the beetle, Scaphinotus interruptus (Men.). Bull South Calif Acad Sci 45:34-36

Kavanaugh DH (1992) Carabid beetles (Insecta: Coleoptera: Carabidae) of the Queen Charlotte Islands, British Columbia. Memoir Calif Acad Sci No 16

Kielty JP, Allen-Williams LJ, Underwood N et al (1996) Behavioral responses of three species of ground beetles (Coleoptera: Carabidae) to olfactory cues associated with prey and habitat. J Ins Behav 9:237-250

Krumbiegel I (1960) Die Rudimentation. Gustav Fischer, Stuttgart
Lindroth CH (1961) The ground beetles (Carabidae excl. Cicindelinae) of Canada and Alaska. Parts 1-6. Opusc Ent

Maron JL, Vila M (2001) When do herbivores affect plant invasion? Evidence for the natural enemies and biotic resistance hypotheses. Oikos 95:361-373

McFrederick QS, Fuentes JD, Roulston T et al (2009) Effects of air pollution on biogenic volatiles and ecological interactions. Oecologia 160:411-420

Müller-Schärer H, Schaffner U, Steinger T (2004) Evolution in invasive plants: implications for biological control. Trends Ecol Evol 19:417-422

Oberholzer F, Frank T (2003) Predation by the carabid beetles Pterostichusmelanarius and Poeciluscupreus on slugs and slug eggs. Biocontrol Sci Technol 13:99-110

Price PW, Bouton CE, Gross P et al (1980) Interactions among 3 trophic levels-influence of plants on interactions between insect herbivores and natural enemies. Ann Rev Ecol Syst 11:41-65

Quick HE (1960) British Slugs (Pulmonata: Testacellidae, Arionidae, Limadicae). Bull Brit Mus (Nat Hist) Zool 6:106-226

Sharkey TD, Chen XY, Yeh S (2001) Isoprene increases thermotolerance of fosmidomycin-fed leaves. Plant Physiol 125:2001-2006

Smith L, Beck JJ (2013) Effect of mechanical damage on emission of volatile organic compounds from plant leaves and implications for evaluation of host plant specificity of prospective biological control agents of weeds. Biocontrol Sci Technol 23:880-907

South A (1992) Terrestrial Slugs: Biology, ecology and control. Chapman \& Hall, London

Spence JR, Spence D (1988) Of ground-beetles and men: introduced species and the synanthropic fauna of western Canada. Ent Soc Can 144:151-168

Symondson WOC, Glen DM, Wiltshire CW et al (1996) Effects of cultivation techniques and methods of straw disposal on predation by Pterostichus melanarius (Coleoptera: Carabidae) upon slugs (Gastropoda: Pulmonata) in an arable field. J Appl Ecol 33:741-753

Thiele HU (1977) Carabid beetles in their environments. Zoophysiol Ecol 10:1-369

Tholl D, Boland W, Hansel A et al (2006) Practical approaches to plant volatile analysis. Plant J 45:540-560

Tulli MC, Carmona DM, Lopez AN et al (2009) Predation on the slug Deroceras reticulatum (Pulmonata: Stylommatophora) by Scarites anthracinus (Coleoptera: Carabidae). Ecologia Austral 19:55-61

Turlings TCJ, Tumlinson JH, Lewis WJ (1990) Exploitation of herbivore-induced plant odors by host-seeking parasitic wasps. Science 250:1251-1253

Vet LEM, Dicke M (1992) Ecology of infochemical use by natural enemies in a tritrophic context. Ann Rev Entomol 37:141-172

Wareing DR (1986) Directional trail following in Deroceras reticulatum (Muller). J Moll Stud 52:256-258

Weber DC, Kavanaugh DH (1992) A new locality record for Scaphinotus longiceps Van Dyke (Coleoptera: Carabidae), with notes about habitat. Coleopt Bull 46:394-396

Weissbecker B, Van Loon JJA, Posthumus MA et al (2000) Identification of volatile potato sesquiterpenoids and their olfactory detection by the two-spotted stinkbug Perillus bioculatus. J Chem Ecol 26:1433-1445

Wheater CP (1989) Prey detection by some predatory Coleoptera. J Zool Soc London 218:171-185

Wheeler GS, Schaffner U (2013) Improved understanding of weed biological control safety and impact with chemical ecology: a review. Invasive Plant Sci Manag 6:16-29

Wilson LM, Jette C, Conett J et al (2003) Biology and Biological Control of Yellow Starthistle. Forest Health Technology Enterprise Team Publications, USDA Forest Service. http://www.fs. fed.us/foresthealth/technology/pdfs/Starthistle.pdf. Accessed 11 October 2011 
Woods M, Pitcairn J, Joley D (2000) Sequential impacts of endemic pathogens, exotic mollusks and insects on yellow starthistle (Centaurea solstitialis L.) in California. Proceedings of the X International Symposium on the Control of Biological Weeds. Montana State University, Bozeman, Montana, pp 807-814
Yuan JS, Himanen SJ, Holopainen JK, Chen F, Stewart Jr CN (2009) Smelling global climate change: mitigation of function for plant volatile organic compounds. Trends ecol evol 24:323-331 